\title{
EVALUATING THE EFFECTIVENESS OF SPEED REDUCTION MARKINGS IN HIGHWAY TUNNELS
}

\author{
Hongliang WAN ${ }^{1}$, Zhigang $\mathrm{DU}^{2 *}$, Qixiang $\mathrm{YAN}^{3}$, Xiaohong $\mathrm{CHEN}^{4}$ \\ ${ }^{1,4}$ Key Laboratory of Road and Traffic Engineering, Tongji University, China \\ ${ }^{2}$ School of Transportation, Wuhan University of Technology, China \\ ${ }^{3}$ Key Laboratory of Transportation Tunnel Engineering, Southwest Jiaotong University, China
}

Received 11 April 2016; revised 15 October 2016, 21 February 2017; accepted 20 March 2017

\begin{abstract}
As typical weak visual reference systems, highway tunnels have low illumination, monotonous environment and few references, which may cause severe visual illusion and reduce drivers' speed perception ability. Thus, drivers tend to underestimate their driving speed, which may induce speeding behaviours that result in rear-end collisions. The cost-effective pavement markings installed on both sides of the lane or shoulder may make drivers overestimate their speed. This perception can help ensure safe driving and regulate driving behaviour effectively. This study analyses the effects of sidewall markings in typical low luminance highway tunnels, specifically observing how their angles and lengths affect the driver's speed perception. A three-dimensional model of highway tunnels was built in a driving simulator. Psychophysical tests of speed perception were carried out by the method of limits. The simulation tests studied the Stimulus of Subjectively Equal Speed (SSES) and reaction time in relation to sidewall markings with different angles. Furthermore, based on the optimal angle, the effects of sidewall marking with different lengths on speed perception were also analysed. The test results reveal that the angle and length of sidewall markings have a significant impact on the driver's SSES and reaction time. Moreover, the level of speed overestimation decreases with the increase of angle or length of sidewall marking. As the angle of sidewall marking gradually increases, the maximum reaction time first increases and then decreases. Within the angle of sidewall marking of $15^{\circ}$, the subjects have the highest speed overestimation and an easy speed judgment. This may due to Zöllner illusion, the driver's perception of lane width shrinks may induce deceleration behaviour.
\end{abstract}

Keywords: traffic safety, highway tunnel, speed perception, reaction time, stimulus of subjectively equal speed.

\section{Introduction}

China has the largest number of highway tunnels in the world. As of 2015, there were 14006 highway tunnels in this country, with a total length of $12683900 \mathrm{~m}$. The dark, narrow, and monotonous environment in highway tunnels offers few reference points and is prone to cause severe visual illusion (Du et al. 2014). Thus, drivers tend to underestimate their driving speed, which can induce speeding behaviours that result in rear-end collisions. Surveys from the Highway Traffic Police Department in China reveal that $38 \%$ of traffic accidents are closely related to drivers' illusion of their driving speed (Zhang et al. 2014). Additionally, a domestic survey shows that up to $40 \%$ of the accidents occurring in the Yuyuan highway and Shangsan highway are attributed to speeding (Guo 2006). However, there are close links between real speed and perception speed; namely, the increase in a driver's perception speed is about two times the decrease in real speed (Recarte,
Nunes 1996). Therefore, it is worthwhile to explore an effective way to control the driving speed in highway tunnels by identifying ways to increase the driver's perception speed, lowering the real speed, and ultimately reducing the accident rate and intensity.

While driving in highway tunnels, drivers tend to lose or reduce the ability to assess their own speed. It is probably due to the lack in the drivers' peripheral vision of the visual stimulations compared to open road sections. In the field, information from the surrounding landscape is often used unconsciously by drivers as an external reference for speed perception (Wan et al. 2016). What's more, lighting is certainly a primary factor that affect the driving performance in highway tunnels. Yeung found that drivers perceived artificial lighting as impairment in their visual performance when compared driver's perspective in open road sections and highway tunnels (Yeung et al. 2013).

${ }^{*}$ Corresponding author. E-mail: zhig_du7@163.com 
By means of driving simulator experimentation, Domenichini analysed the driving performance in Light-Emitting Diode (LED) lighted tunnels and High-Pressure Sodium (HPS) lighted tunnels, the results revealed that simulated LED lights often induced a better driving behaviour under some aspects (Domenichini et al. 2017). However, the lighting system represents the most expensive operative cost of a tunnel. It is essential to find solutions and technologies that can reduce energy costs without affecting traffic safety.

There are many speed control methods, such as setting speed limit signs, auxiliary driving system, etc. The real-time speed limit sign is underdeveloped. Therefore, it is difficult to be followed by the drivers. Because of the high cost, the current penetration rate of auxiliary driving system is very low. As an alternative low-cost solution for traffic safety, pavement markings can use the visual illusion to control the driving speed. It is easy for the drivers to understand and accept, and it also has a good visual recognition under low luminance environment. Transverse pavement markings installed on both sides of the lane or shoulder and placed at an angle to the driving direction can make drivers overestimate their real speed and feel that the lane is gradually narrowing. Such marking treatment can regulate driving behaviour and ensure traffic safety effectively (Drakopoulos, Vergou 2003; Galante et al. 2010). However, the enclosed environment in highway tunnels is conducive to dust accumulation on pavement caused by vehicle exhaust, which decreases the reflectivity of such pavement marking treatments. Fortunately, installing marking treatments on the tunnel sidewall can mitigate these adverse effects to a certain extent.

Pavement markings, especially the transverse lines with decreasing spacing, have been shown to decrease vehicle speeds in some situations (Denton 1980; Charlton 2007a, 2007b). According to Godley, both transverse and vertical markings at constant or decreasing spacing can lead to speed reduction. In addition, transverse markings contribute more to speed reduction than vertical markings (Godley et al. 2000). The transverse pavement marking treatments can effectively reduce curve speeds, especially shortly after initial installation. Moreover, such treatment was more effective at reducing speed in the lane next to the shoulder than in the median lane (Gates et al. 2008).

Chevron pavement markings or herringbone pavement markings can both produce an appreciable reduction in speed as well as improved drivers' lane position (Godley et al. 2002; Charlton 2007a, 2007b). Such treatments can also be used to highlight perceptual cues in highway curves, ramps or tunnels (Retting et al. 2000; Gilmore et al. 2013). Hunter investigated the effectiveness of converging chevron pavement markings in reducing vehicle speeds on freeway ramps. The results indicated that effect was most pronounced shortly after implementation of the markings. By the ninth month after installation, however, the effect had dropped to less than $5 \mathrm{~km} / \mathrm{h}$ difference in the mean speed (Hunter et al. 2010). Ding used driving simulation to analyse the effectiveness of speed reduction markings in downhill sections. The results revealed that longitudinal speed reduction markings were more effective than transverse speed reduction markings (Ding et al. 2015). Xia focused on the design pattern of city tunnel sidewall and the fuzzy elevation method was applied to evaluate the performance of wave pattern and arrow pattern. Moreover, the comfort and rationality of the new design patterns had been verified (Xia et al. 2017).

The perception of speed can be influenced by the orientation of stimuli relative to their motion axis (Georges et al. 2002). In fact, the installation of pavement markings that have a certain angle to the driving direction may create the Zöllner illusion. Consequently, the driver's perception of lane width shrinks (or expands), which can induce deceleration (or acceleration) (Lewis-Evans, Charlton 2006; Park et al. 2012). Moreover, when the angle of the pavement markings ranges between $10-15^{\circ}$, the effect of the Zöllner illusion reaches peak impact (Prinzmetal, Beck 2001; Wenderoth, Burke 2006).

The size (width, height) of the stimulus along the motion path is crucial for the speed misjudgement (Castet et al. 1993; Ryan, Zanker 2001). Consequently, the length change of sidewall marking can influence the driver's speed perception, and may contribute to speed control in highway tunnels.

A review of previous studies showed the following issues with research regarding speed control methods based on pavement marking:

- a lack of quantitative investigation on how the angle and length of sidewall marking affects driver's speed perception;

- to evaluate speed perception, speed is usually chosen as the single index, which means the degree-ofdifficulty concerning that speed perception is not studied;

- previous studies paid more attention to the application of pavement markings, and were not developed to analyse the speed perception impact of sidewall marking in highway tunnels;

- previous studies focused on the effect of marking treatment on speed control in highway curves or highway ramps, however, that a quantitative investigation of speed perception in the low luminance conditions typically encountered in China's highway tunnels need further research.

Speeding behaviour results in an increase of traffic accidents in China's highway tunnels. Installing sidewall marking is a low-cost traffic safety solution that can improve a driver's speed perception and effectively control driving speeds. With the help of Stimulus of Subjectively Equal Speed (SSES) and reaction time, this paper quantitatively investigates how the angle and length of sidewall markings affect the drivers' speed perception in tunnels by using a driving simulator. The results of this research can provide a reference guide for the effective design of sidewall marking. 


\section{Materials and methods}

There is a high risk associated with real vehicle testing in highway tunnels as well as a dependency on tunnel sidewall marking installation, which would affect traffic flow and management while increasing testing expenses. In order to overcome these difficulties and avoid the poor reproducibility inherent in that method, this study used $A u$ todesk $3 d s$ Max (https://www.autodesk.com/products/3dsmax/overview) to establish a highway tunnel driving simulation model (Wan et al. 2015). Autodesk $3 d s$ Max ${ }^{\circ}$ is a $3 \mathrm{D}$ computer graphics program, which can be used to making 3D animations, models and images. In addition, the driving simulator in this paper can be supported by Autodesk $3 d s$ Max. The realistic driving environment is set by $V$-ray. The $V$-ray is a third-party render engine plug-in for Autodesk $3 d s \mathrm{Max}$. It uses global illumination algorithms, which can enhance the immersion aspect of a simulation experiment. Then, an E-Prime 2.0 was used to conduct the psychophysical speed perception tests. EPrime 2.0 software is commonly used in psychological experiments and can produce text, image and sound stimuli. Finally, test data were statistically analysed by Origin 8.5 and SPSS 20.0.

\subsection{Driving simulator}

The test was conducted in the Wuhan University of Technology, Intelligent Transport System, High Definition (WUTITS-HD), an advanced driving simulator produced by Wuhan University of Technology (Figure 1) (Wan et al. 2015). The driving simulator used in the experimentation is a full scale, dynamic simulator, with steering wheel with force feedback. The visual system includes 5 LED digital screens providing a $180^{\circ}$ forward field of view and 3 LED screens for the rear view mirrors, the screens all have a resolution of $720 \mathrm{p}(1280 \times 720$ pixels). Sounds and noise are generated by a multichannel audio system. The effective sampling rate of this simulator is $1 \mathrm{~Hz}$. The simulator can be applied to study the issues related to road traffic safety under controlled experimental conditions. These issues include driver behaviour analysis, automatic driving simulation and traffic guidance design.

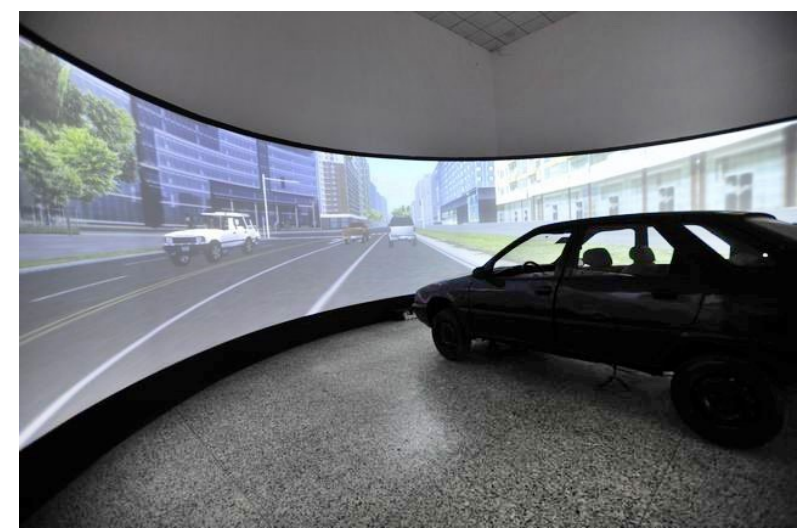

Figure 1. Advanced moving base simulator

\subsection{Participants}

Participants were selected according to the following criteria: possession of a Chinese valid driver's license, with at least 3 years of driving experience, an annual driving distance greater than $6000 \mathrm{~km}$. Statistically, the ratio of male and female drivers in China is 7:3 according to the related report of the Ministry of Public Security in 2012 (Zhang et al. 2014). Accordingly, a total of 20 subjects were selected for this test, including 14 males and $6 \mathrm{fe}-$ males (Table 1). The ages of the subjects ranged from 22 to 47 (mean $=29.9$ years and $S D=7.4$ years). Their driving experience (measured in terms of years of driving license possession) varied between 3 years and 25 years (mean $=$ 9.5 years and $S D=7.5$ years). All the participants had normal or corrected eyesight above 5.0.

Table 1. Details of participants

\begin{tabular}{|c|c|c|c|}
\hline Series & Age [year] & Driving experience [year] & Gender \\
\hline 1 & 22 & 3 & female \\
\hline 2 & 23 & 3 & female \\
\hline 3 & 23 & 3 & male \\
\hline 4 & 24 & 3 & male \\
\hline 5 & 24 & 4 & male \\
\hline 6 & 24 & 4 & male \\
\hline 7 & 24 & 4 & female \\
\hline 8 & 25 & 4 & male \\
\hline 9 & 25 & 5 & female \\
\hline 10 & 27 & 5 & male \\
\hline 11 & 28 & 6 & male \\
\hline 12 & 28 & 7 & male \\
\hline 13 & 30 & 9 & male \\
\hline 14 & 31 & 10 & male \\
\hline 15 & 35 & 13 & female \\
\hline 16 & 36 & 16 & male \\
\hline 17 & 38 & 19 & male \\
\hline 18 & 41 & 22 & female \\
\hline 19 & 44 & 25 & \\
\hline 20 & 47 & & male \\
\hline
\end{tabular}

\subsection{Test method}

The method of limits, also called the method of minimal change, is a direct method to measure threshold (Guo, Yang 2004). This method is used to find the instantaneous transition point or threshold position from one reaction to another by changing the stimulus (in either an increasing or decreasing order) in small, equal intervals.

SSES is defined as the real driving speed in a comparison scene in which the perceived speed is the same as that in the standard scene (Shen et al. 2005). The method of limits is used in this paper to determine the SSES. Two 
speed stimuli are adopted in the test, one increasing and the other decreasing. The strength of the increasing stimulus gradually increases from a low value where the perceived speed in the comparison scene is lower than that in the standard scene. In contrast, the stimulus strength in a decreasing order decreases from a high value, starting from a higher perceived speed in the comparison scene than the standard scene. Once the subject feels the opposite stimulus (i.e. the perceived speed in the comparison scene slower than that in the standard scene changes to faster, and vice versa), the real speed in the comparison scene is the SSES. The obtained threshold has a certain level of error (i.e. an inherent increment exists in all of the thresholds for increasing stimuli and vice versa). The ABBA method was used in this study to correct this error, where ' $\mathrm{A}$ ' denotes the speed stimulus in an increasing sequence and ' $\mathrm{B}$ ' denotes the stimulus in a decreasing sequence (Shaughnessy et al. 2014; Weafer, Fillmore 2015). The tests were carried out in a sequence of ABBA. To guarantee the reliability, each group test was repeated four times. As a result, each test has $20 \times 4 \times 4=320$ sample points. The E-Prime 2.0 software is an operating system used to conduct psychology experiments. In this paper, $E$ Prime 2.0 was used to conduct the process described above.

Reaction time is one of the most common response variables in psychology (Guo, Yang 2004). In this paper, the reaction time is defined as the interval of time between the application of a stimulus and the detection of a reaction. E-Prime 2.0 software can automatically record the period between stimulus and reaction.

\subsection{Test procedure}

This paper adopted a repeating method, which involved a large amount of data but created high accuracy and reliability, offering the advantages of simple operation, excellent repeatability and high safety of the video simulation test.

The detailed operation steps are presented as follows:

- before the formal test, the subjects have to get familiar with the test for 10-15 min with the help of experiment operators, performing three preexperiments randomly;

- a laptop computer was used to run the E-Prime 2.0 software in the simulator. The video simulation test was started by pressing ' $Q$ ' on the keyboard, which triggers the video to play on the simulator screen. The distance between the screen and the subject's eyes is $6 \mathrm{~m}$;

- $3 \mathrm{sec}$ of preparation time is reserved for each subject before starting the comparison video;

- the subject is required to watch the road ahead and judge the relative speed of the comparison stimulus in relation to the standard stimulus as soon as possible (within $10 \mathrm{sec}$ );

- if the subject feels that the perceived speed in the left video screen is higher than that in the right video screen, he or she should press the left button of the handle. On the contrary, if the perceived speed in the right video screen appears higher than that of the left video screen, the subject should press the right button;

- after each test with a certain angle and length of visual information, the test is stopped and the subject takes a 3 min break.

\subsection{Precision checks}

There is a certain distortion for simulation test compared to the field test. Experiments were carried out in this study to examine the precision of the simulation test compared to the field test. Figure 2 illustrates the field scene as compared to the simulation scene (Wan et al. 2015). A driving speed of $74 \mathrm{~km} / \mathrm{h}$ was taken in the field scene and a speed of $74 \pm 20 \mathrm{~km} / \mathrm{h}$ (with a minimum interval of $2.5 \mathrm{~km} / \mathrm{h}$ ) was taken in the simulation scene. The SSES measured by the method of limits was $75.12 \mathrm{~km} / \mathrm{h}$. The error between the predicted speed from the proposed model and the measured result is $-1.50 \%$, which is well within a $5 \%$ margin of error. The results from one-sample $t$-tests show that the $p$-value exceeds 0.05 (Table 2). The accuracy of the model, therefore, has no significant difference between the simulation test and the field test, thereby validating the effectiveness of the proposed simulation model.
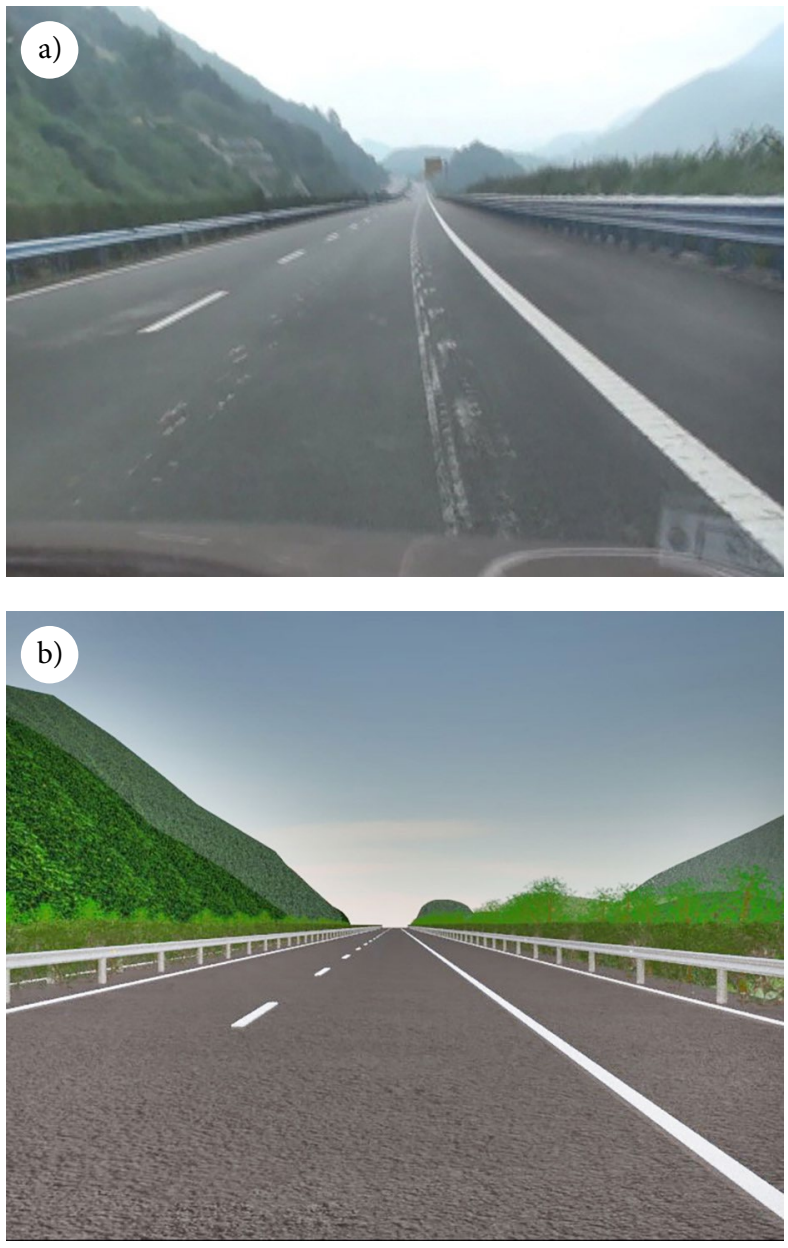

Figure 2. Verification of model accuracy: $\mathrm{a}$ - field scene; $\mathrm{b}$ - simulation scene 
Table 2. One-sample $t$-test

\begin{tabular}{|c|c|c|c|c|c|}
\hline & \multicolumn{5}{|c|}{ Test value $=74 \mathrm{~km} / \mathrm{h}$ (the speed of field scene) } \\
\hline & \multirow{2}{*}{$N$} & \multirow{2}{*}{$p$-value } & \multirow{2}{*}{ Mean $[\mathrm{km} / \mathrm{h}]$} & \multicolumn{2}{|c|}{$95 \%$ confidence interval of the difference } \\
\hline & & & & lower & upper \\
\hline The speed of simulation scene & 40 & 0.091 & 75.12 & 73.841 & 76.404 \\
\hline
\end{tabular}

\section{Speed perception test considering the angle of sidewall marking}

\subsection{Test scene design}

The test scenes were classified into standard test scene and comparison test scene. The standard scene is the driving simulation of a common section of highway (Figure 2b). According to the Technical Standard of Highway Engineering (2014), a design speed of $80 \mathrm{~km} / \mathrm{h}$ should have a median strip width of $2 \mathrm{~m}$, a lane width of $3.75 \mathrm{~m}$, and left and right hard shoulder widths of 0.75 and $2.5 \mathrm{~m}$, respectively. The comparison scene refers to the driving simulation representing the middle of a highway tunnel. The highway tunnel should be designed as follows: the separated independent double hole and the construction gauge height is $5 \mathrm{~m}$, the curb width is $0.75 \mathrm{~m}$, and the left and right shoulder widths are 0.5 and $0.75 \mathrm{~m}$, respectively.

The simulation test used the common section of highway driving video as the standard stimulus, and then used the sidewall markings, which have different angles to the driving direction, as comparison stimuli. The speed of the standard stimulus was $80 \mathrm{~km} / \mathrm{h}$. The speed of the comparison stimuli ranged from 55 to $75 \mathrm{~km} / \mathrm{h}$ with an interval of $2.5 \mathrm{~km} / \mathrm{h}$. The standard scene remained the same throughout the test. The design of the highway tunnel sidewall markings is shown in Figure 3. The values of $a, b$ and $l$ are $5,0.5$ and $2.5 \mathrm{~m}$, respectively. Additionally, the range of $\theta$ is $15 \div 165^{\circ}$ with an interval of $15^{\circ}$. Temporal frequency is the number of occurrences of a repeating event per unit time, and the temporal frequency value of sidewall marking can be obtained by the value of $a$.
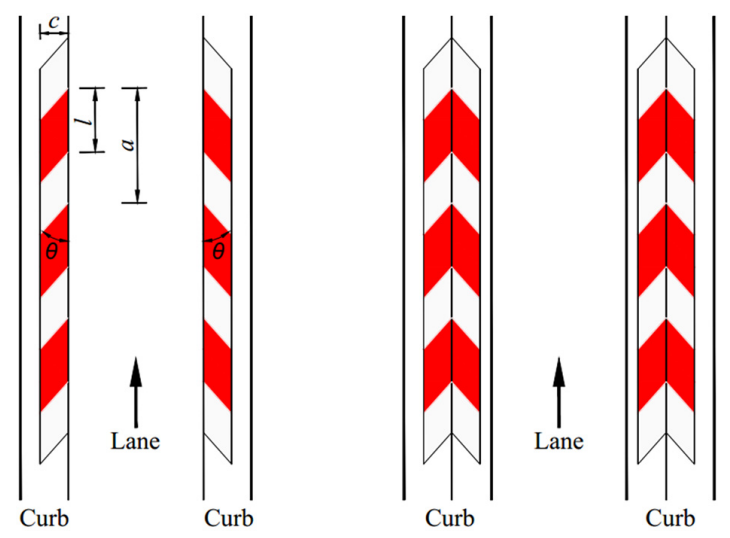

Floor Plan

Flat Pattern

Figure 3. Design of sidewall markings in highway tunnels
The comparison test scenes are shown in Figure 4, and the detailed scenes are presented as follows: Scene 1 $\left(\theta=15^{\circ}\right)$, Scene $2\left(\theta=30^{\circ}\right)$, Scene $3\left(\theta=45^{\circ}\right)$, Scene 4 $\left(\theta=60^{\circ}\right)$, Scene $5\left(\theta=75^{\circ}\right)$, Scene $6\left(\theta=90^{\circ}\right)$, Scene 7 $\left(\theta=105^{\circ}\right)$, Scene $8\left(\theta=120^{\circ}\right)$, Scene $9\left(\theta=135^{\circ}\right)$, Scene $10\left(\theta=150^{\circ}\right)$ and Scene $11\left(\theta=165^{\circ}\right)$.

The $100 \%$ standard luminance refers to the Guidelines for Design of Lighting of Highway Tunnels (2014), using the lighting design in the Enlai highway tunnel in the Hubei province as an example. 100 W of HPS was arranged bilaterally and symmetrically with an interval of $10 \mathrm{~m}$. The luminous efficacy of the HPS is $110 \mathrm{~lm} / \mathrm{W}$ with a colour temperature of $1800 \mathrm{~K}$ and an average pavement luminance of $4.5 \mathrm{~cd} / \mathrm{m}^{2}$. A single-sided lamp arrangement was used for the $50 \%$ standard luminance. Additionally, the power of two headlights is $60 \mathrm{~W}$ with a colour temperature of $1800 \mathrm{~K}$.

\subsection{Test results of SSES}

The distribution of SSES under different values of $\theta$ are obtained by E-Prime 2.0 software using the method of limits. The results are shown in Figure 5 and Table 3.
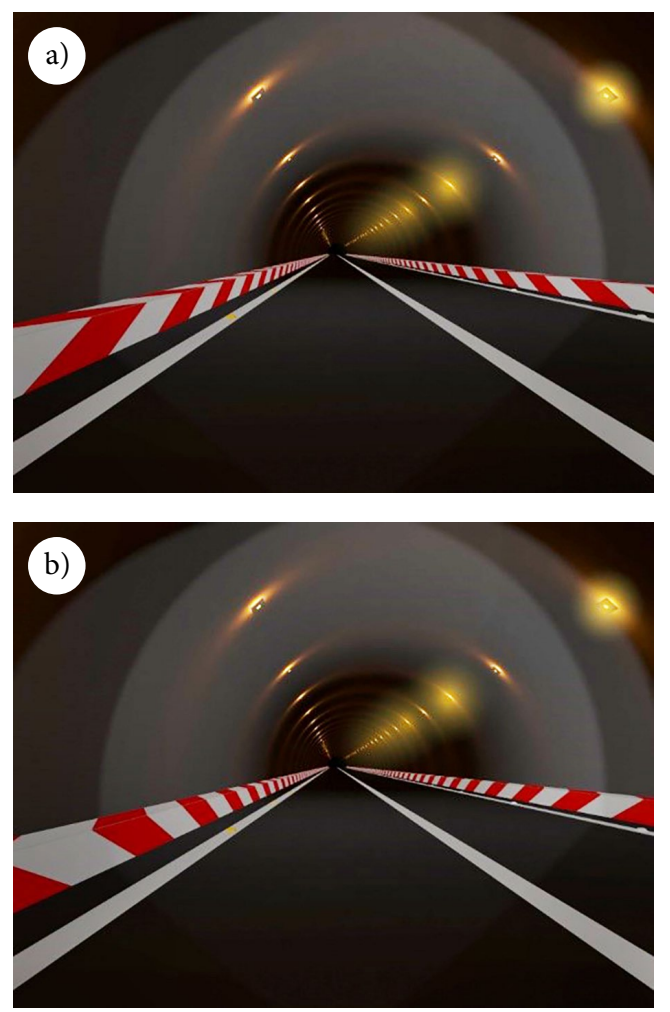

Figure 4. Parts of comparison test scenes: $\mathrm{a}-\theta=15^{\circ} ; \mathrm{b}-\theta=165^{\circ}$ 


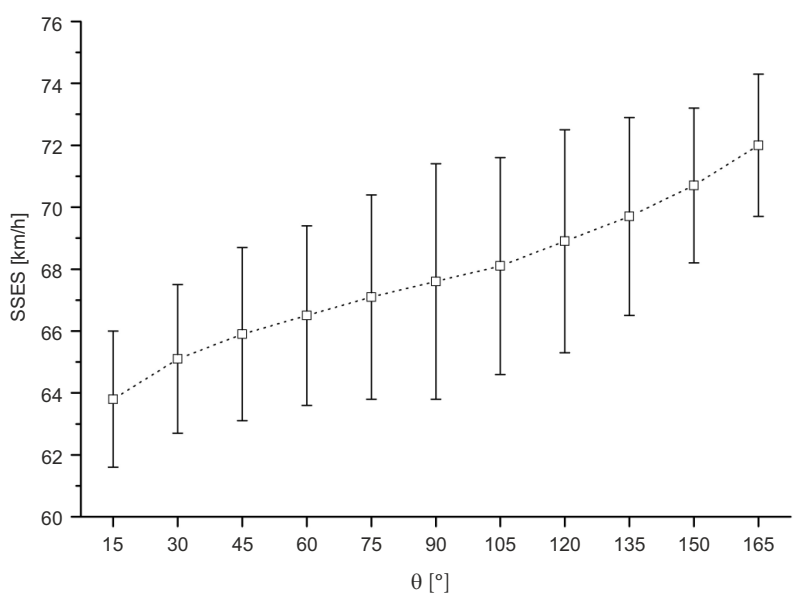

Figure 5. Distribution of SSES

Table 3. Degree of speed illusion

\begin{tabular}{|c|c|c|c|}
\hline $\begin{array}{c}\text { Test } \\
\text { series }\end{array}$ & $\begin{array}{c}\text { Test conditions, } \\
\theta\left[{ }^{\circ}\right]\end{array}$ & $\begin{array}{c}\text { SSES } \\
{[\mathrm{km} / \mathrm{h}]}\end{array}$ & $\begin{array}{c}\text { Degree of speed } \\
\text { illusion }[\%]\end{array}$ \\
\hline Test 1 & 15 & $63.8 \pm 2.2$ & $+20.3 \pm 2.8$ \\
\hline Test 2 & 30 & $65.1 \pm 2.4$ & $+18.6 \pm 3.0$ \\
\hline Test 3 & 45 & $65.9 \pm 2.8$ & $+17.6 \pm 3.5$ \\
\hline Test 4 & 60 & $66.5 \pm 2.9$ & $+16.9 \pm 3.6$ \\
\hline Test 5 & 75 & $67.1 \pm 3.3$ & $+16.1 \pm 4.1$ \\
\hline Test 6 & 90 & $67.6 \pm 3.8$ & $+15.5 \pm 4.8$ \\
\hline Test 7 & 105 & $68.1 \pm 3.5$ & $+14.9 \pm 4.4$ \\
\hline Test 8 & 120 & $68.9 \pm 3.6$ & $+13.9 \pm 4.5$ \\
\hline Test 9 & 135 & $69.7 \pm 3.2$ & $+12.9 \pm 4.0$ \\
\hline Test 10 & 150 & $70.7 \pm 2.5$ & $+11.6 \pm 3.1$ \\
\hline Test 11 & 165 & $72.0 \pm 2.3$ & $+10.0 \pm 2.9$ \\
\hline
\end{tabular}

Notes: speed in the standard scene $=80 \mathrm{~km} / \mathrm{h}$; the degree of speed illusion $=($ speed in the standard scene-SSES $) /$ speed in the standard scene; '+' denotes speed overestimation, '-' denotes speed underestimation.

From Figure 5 and Table 3, the following can be observed:

- the descending order of the degree of speed illusion for different angles is $15^{\circ} \rightarrow 30^{\circ} \rightarrow 45^{\circ} \rightarrow 60^{\circ} \rightarrow$ $75^{\circ} \rightarrow 90^{\circ} \rightarrow 105^{\circ} \rightarrow 120^{\circ} \rightarrow 135^{\circ} \rightarrow 150^{\circ} \rightarrow 165^{\circ}$.

- the angle of the sidewall marking has a significant impact on the SSES $(p=0.009<0.05)$, which was analysed by one-way ANalysis Of VAriance (ANOVA) in SPSS 20.0 ( $p$-value $=0.05)$.

\subsection{Test results of reaction time}

First, obtained the average value of reaction time under different conditions of $\theta$, and then completed the normal curve fitting of the average value using Origin 8.5:

$$
y=\frac{1}{\sigma \cdot \sqrt{2 \cdot \pi}} \cdot e^{-\frac{\left(x-x_{c}\right)^{2}}{2 \cdot \sigma^{2}}},
$$

where: $e$ and $\pi$ are constants; $x$ is the independent variable representing driving speed; $y$ is the dependent variable representing reaction time; $x_{c}$ is the expected value of the driving speed; $\sigma$ is the standard deviation of the driving speed.

The derived distribution of reaction time is shown in Figure 6.

Table 4 shows the related parameters of normal curve fitting.

From Figure 6 and Table 4, the following can be observed:

- as the angle of the sidewall marking gradually increases, the maximum reaction time first increases gradually, and then gradually decreases. The maximum reaction time value $(2.8 \mathrm{sec})$ occurs at $90^{\circ}$. The maximum reaction time reaches its relative minimum value ( 2.46 or $2.35 \mathrm{sec}$ ) when the angle is 15 or $165^{\circ}$;

- the angle of the sidewall marking has a significant impact on the maximum reaction time $(p=0.014<$ $0.05)$, which was analysed by one-way ANOVA in SPSS 20.0 ( $p$-value $=0.05)$.

a)

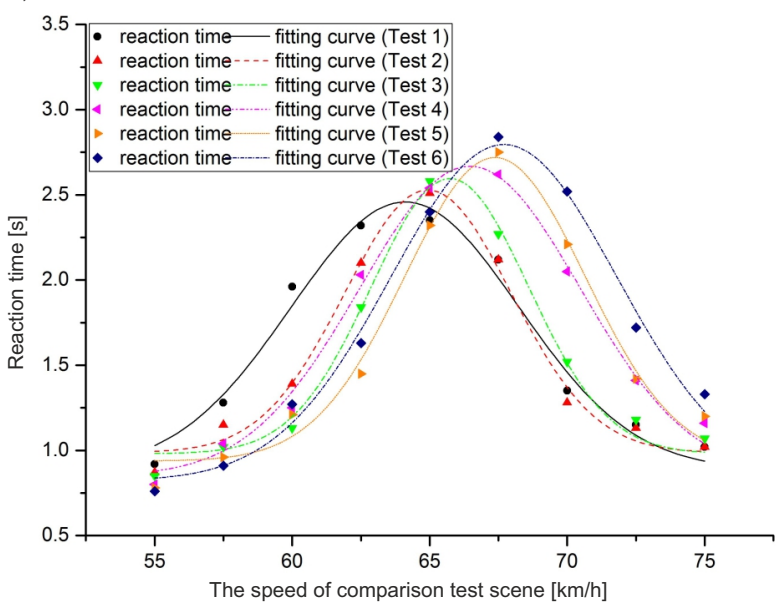

b)

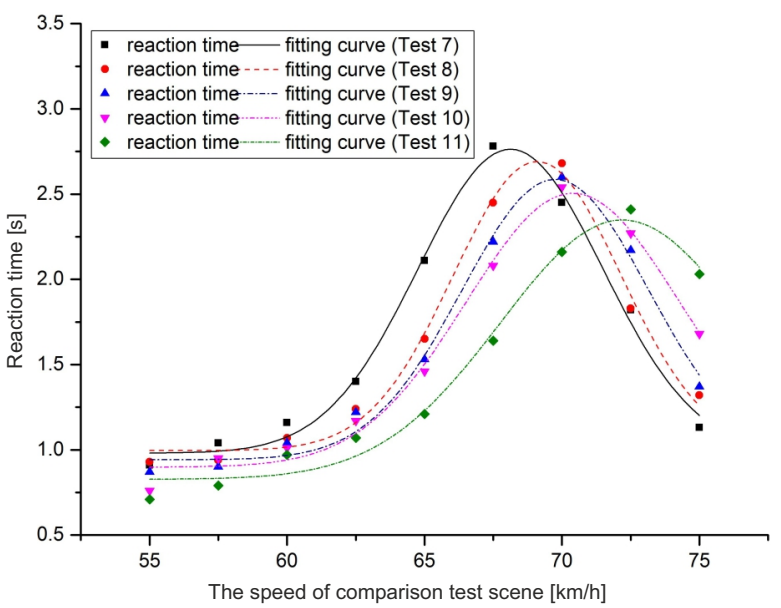

Figure 6. Distribution of reaction time: $a$ - tests $1 \div 6$; b - tests $7 \div 11$ 
Table 4. Related parameters of normal fitting

\begin{tabular}{|c|c|c|c|c|}
\hline Test series & $\begin{array}{c}\text { Test conditions, } \\
\theta\left[{ }^{\circ}\right]\end{array}$ & $R^{2}$ & $x_{c}[\mathrm{~km} / \mathrm{h}]$ & $y_{c}[\mathrm{sec}]$ \\
\hline Test 1 & 15 & 0.960 & 64.11 & 2.46 \\
\hline Test 2 & 30 & 0.976 & 64.93 & 2.53 \\
\hline Test 3 & 45 & 0.977 & 65.74 & 2.60 \\
\hline Test 4 & 60 & 0.983 & 66.46 & 2.67 \\
\hline Test 5 & 75 & 0.968 & 67.38 & 2.72 \\
\hline Test 6 & 90 & 0.983 & 67.70 & 2.80 \\
\hline Test 7 & 105 & 0.986 & 68.13 & 2.76 \\
\hline Test 8 & 120 & 0.984 & 69.10 & 2.70 \\
\hline Test 9 & 135 & 0.983 & 69.76 & 2.59 \\
\hline Test 10 & 150 & 0.982 & 70.40 & 2.51 \\
\hline Test 11 & 165 & 0.976 & 72.20 & 2.35 \\
\hline
\end{tabular}

Note: The maximum reaction time $y_{c}$ occurs at $x=x_{c}$.

Within the angle of sidewall marking of $15^{\circ}$, the subjects have the highest speed overestimation and an easy speed judgment (minimum maximum reaction time). Accordingly, $15^{\circ}$ should be chosen as the value of the angle for sidewall marking design in highway tunnels.

\section{Speed perception test considering the length of sidewall marking}

\subsection{Test scene design}

The standard speed perception test stimulus uses the driving simulation video based on a common section of highway (see Figure $2 \mathrm{~b}$ ). The test used sidewall markings with different lengths as comparison stimuli. The standard stimulus speed was $80 \mathrm{~km} / \mathrm{h}$. The comparison stimuli speed ranged from 55 to $75 \mathrm{~km} / \mathrm{h}$, with an interval of $2.5 \mathrm{~km} / \mathrm{h}$. The standard test scene remained the same throughout the test. The comparison test scenes are shown in Fig. 7 and the detailed scenes are presented as follows: Scene $1(l=1.25 \mathrm{~m})$, Scene $2(l=3.75 \mathrm{~m})$.

\subsection{Test Results}

Fig. 8 shows the SSES distribution and Figure 9 shows reaction time distribution.

From Figures 8-9 and Table 5, it can be seen that:

- the SSES increases with the increase of the length of sidewall marking. Therefore, the test results reveal that speed overestimation is the most obvious when the length of sidewall marking is $1.25 \mathrm{~m}$;

- the maximum reaction time has a minimum value with a length of $1.25 \mathrm{~m}$. Therefore, these results show that subjects were more sensitive to the speed variation when the length of sidewall marking is $1.25 \mathrm{~m}$;

- the length of sidewall marking has a significant impact on the SSES ( $p$-value $=0.027<0.05)$, which was analysed by one-way ANOVA in SPSS 20.0 ( $p$ value $=0.05$ ).
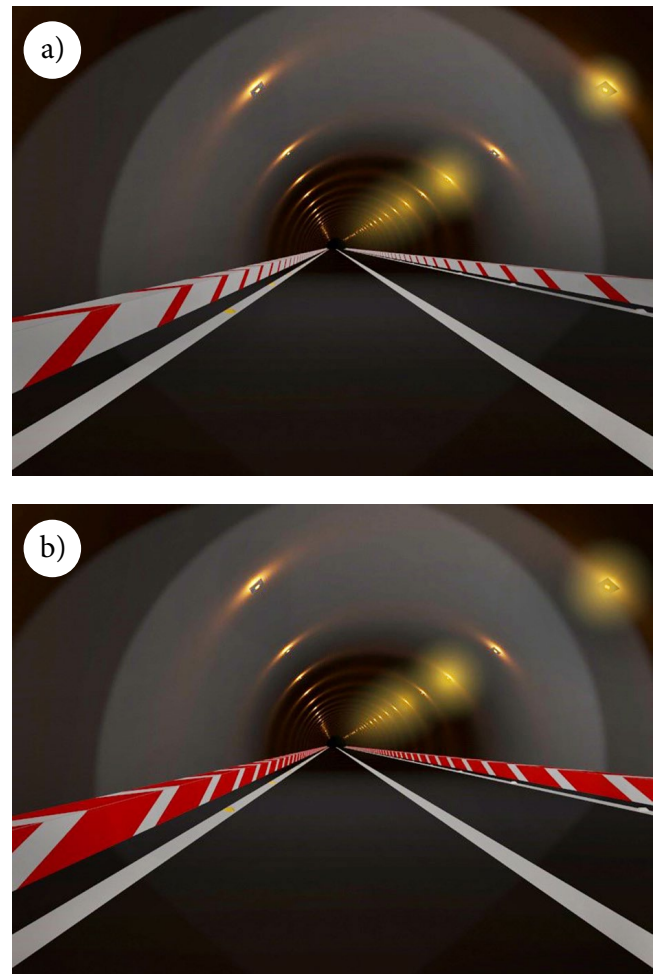

Figure 7. Comparison test scenes: $\mathrm{a}-l=1.25 \mathrm{~m}$; $\mathrm{b}-l=3.75 \mathrm{~m}$

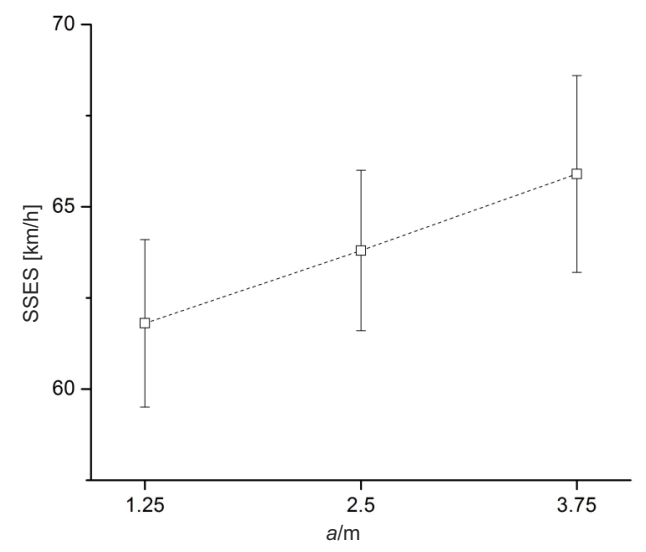

Figure 8. Distribution of SSES

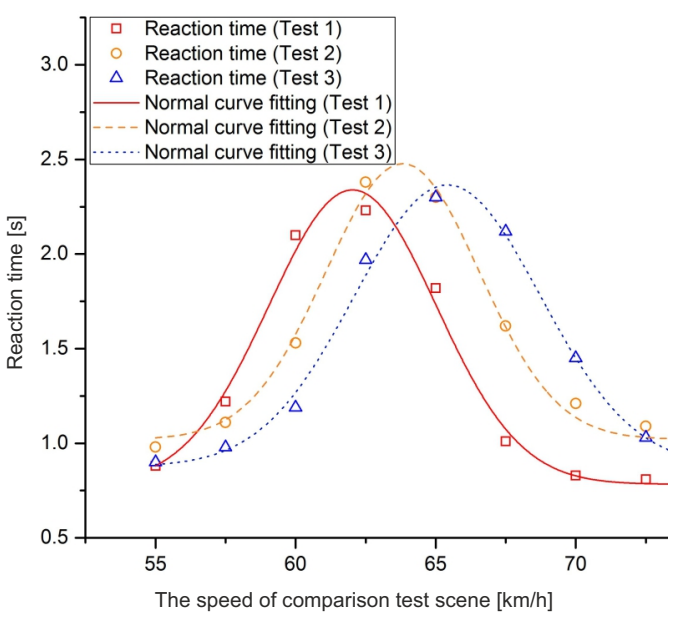

Figure 9. Distribution of reaction time 
- the length of sidewall marking has a significant impact on the maximum reaction time $(p=0.034<0.05)$, which was analysed by one-way ANOVA in SPSS 20.0 ( $p$-value $=0.05)$.

Within the length of sidewall marking of $1.25 \mathrm{~m}$, the maximum speed overestimation occurs and speed judgment is easiest (minimum maximum reaction time). Accordingly, $1.25 \mathrm{~m}$ should be chosen as the value of the length for sidewall marking design in highway tunnels.

Table 5. Degree of speed illusion

\begin{tabular}{|c|c|c|c|c|}
\hline $\begin{array}{c}\text { Test } \\
\text { series }\end{array}$ & $\begin{array}{c}\text { Test } \\
\text { conditions, } \\
l[\mathrm{~m}]\end{array}$ & $\begin{array}{c}\text { SSES } \\
{[\mathrm{km} / \mathrm{h}]}\end{array}$ & $\begin{array}{c}\text { Maximum } \\
\text { reaction } \\
\text { time }[\mathrm{s}]\end{array}$ & $R^{2}$ \\
\hline Test 1 & 1.25 & $61.7 \pm 2.5$ & 2.33 & 0.962 \\
\hline Test 2 & 2.50 & $63.8 \pm 2.2$ & 2.46 & 0.987 \\
\hline Test 3 & 3.75 & $65.5 \pm 2.3$ & 2.37 & 0.958 \\
\hline
\end{tabular}

\section{Discussions}

Using the design forms (such as the width, interval and temporal frequency) of speed reduction markings to control a driver's speed has a number of practical applications and can obtain effective results. However, existing studies always chose the speed index to evaluate the effectiveness of speed reduction markings, especially concerning the maximum speed overestimation (Shen et al. 2005). However, a high level of speed overestimation can easily lead to drivers to experience nervous feelings and increase their mental workload. Therefore, an appropriate level of speed overestimation is beneficial in reducing speeding behaviour and improving traffic safety. Further research is still required to determine exactly what degree of the speed overestimation is most beneficial to traffic safety. This paper introduced the reaction time index from experimental psychology to analyse the workload of speed perception. A shorter reaction time indicates that speed perception is easier, which helps the driver understand and interpret the design of traffic markings.

Generally, the closer the real driving speed in a comparison scene matches the SSES, the longer reaction time the subjects will take to make a speed judgment between the comparison scene and standard scene. Therefore, the maximum reaction time occurs at the speed $x=x_{c}$. However, the low threshold of reaction time can leave drivers more time to deal with emergencies and improve driver's sensitivity to speed variation, which is beneficial to driving safety in highway tunnels.

This paper studied the short-term reaction of drivers to various stimuli. Whereas adaptation causes an underestimation of speed, attention leads to an overestimation of speed (Anton-Erxleben et al. 2013). If the drivers accumulate greater exposure, they may get familiar with the traffic and environmental conditions in highway tunnels. This familiarity could reduce the speed control effect of traffic markings, decrease the accuracy of speed perception and increase the reaction time (Manser, Hancock 2007; Gates

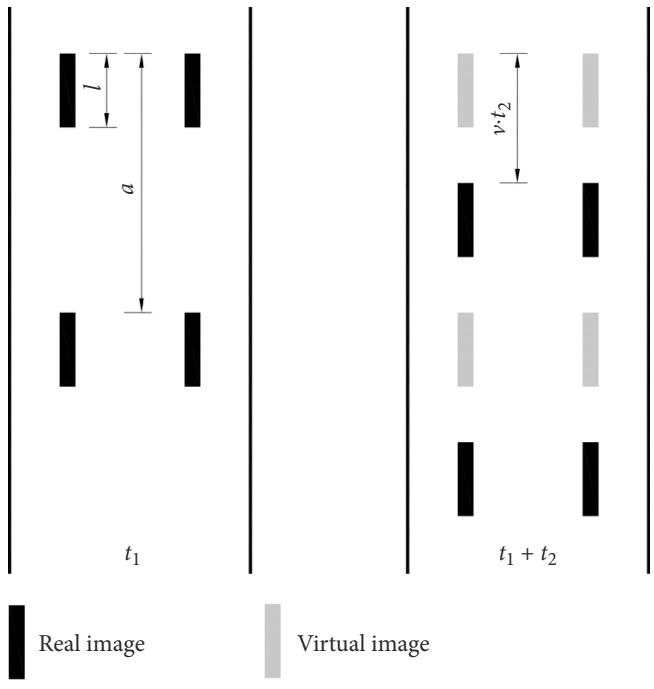

Figure 10. Persistence of vision

et al. 2008). However, the lengths of most highway tunnels are less than $1.0 \mathrm{~km}$ and the normal travel time in highway tunnels in China does not regularly exceed $30-40 \mathrm{sec}$. Overall, the improvements suggested in this paper are beneficial to control speed.

Because of the persistence of vision (Carmel et al. 2007), reducing the length of sidewall marking may increase its temporal frequency in drivers' vision. Figure 10 illustrates the persistence of vision, $t_{1}$ is the duration of persistence of vision, and $v$ is the driving speed. At time $t_{1}+t_{2}$, drivers can see real image and virtual image at the same time; the virtual image can help increase the temporal frequency of traffic marking. This may result in drivers' speed overestimation.

Since $a$ remained the same throughout the test, the temporal frequency of sidewall marking is fixed actually. When the length of white marking is $1.25 \mathrm{~m}$, the subjects have the lowest speed overestimation. However, when the length of red marking is $1.25 \mathrm{~m}$, the subjects have the highest speed overestimation. This may be because the drivers are more sensitive to red marking than the white marking. If the colour of sidewall marking is changed, the results may be quite different.

\section{Conclusions}

The effects of tunnel sidewall markings on the driver's speed perception have been investigated and statistically validated using a driving simulator. Moreover, the SSES and the reaction time are combined to evaluate the driver's visual illusion. Using the appropriate angle and length of sidewall markings can make drivers overestimate their speed and improve their sensitivity to speed variation. This finding can be used to help regulate drivers' unintended acceleration behaviours in highway tunnels in low luminance conditions where there is a lack of ambient visual references. Moreover, a certain degree of speed overestimation can restrain drivers' speeding behaviour 
effectively, which is beneficial to driving safety in highway tunnels.

Further research is needed to examine the transferability of these findings for long-term reaction experiments. In addition, the different conditions (another tunnel section, other lighting conditions or a combination of different variables) could complement this study in future research.

\section{Acknowledgements}

This work was supported by the National Natural Science Foundation of China (No 51578433).

\section{References}

Anton-Erxleben, K.; Herrmann, K.; Carrasco, M. 2013. Independent effects of adaptation and attention on perceived speed, Psychological Science 24(2): 150-159. https://doi.org/10.1177/0956797612449178

Carmel, D.; Saker, P.; Rees, G.; Lavie, N. 2007. Perceptual load modulates conscious flicker perception, Journal of Vision 7(14): 1-13. https://doi.org/10.1167/7.14.14

Castet, E.; Lorenceau, J.; Shiffrar, M.; Bonnet, C. 1993. Perceived speed of moving lines depends on orientation, length, speed and luminance, Vision Research 33(14): 1921-1936.

https://doi.org/10.1016/0042-6989(93)90019-S

Charlton, S. G. 2007a. Delineation effects in overtaking lane design, Transportation Research Part F: Traffic Psychology and Behaviour 10(2): 153-163.

https://doi.org/10.1016/j.trf.2006.09.003

Charlton, S. G. 2007b. The role of attention in horizontal curves: a comparison of advance warning, delineation, and road marking treatments, Accident Analysis \& Prevention 39(5): 873-885. https://doi.org/10.1016/j.aap.2006.12.007

Denton, G. G. 1980. The influence of visual pattern on perceived speed, Perception 9(4): 393-402.

https://doi.org/10.1068/p090393

Ding, H.; Zhao, X.; Rong, J.; Ma, J. 2015. Experimental research on the effectiveness and adaptability of speed reduction markings in downhill sections on urban roads: a driving simulation study, Accident Analysis \& Prevention 75: 119-127. https://doi.org/10.1016/j.aap.2014.11.018

Domenichini, L.; La Torre, F.; Vangi, D.; Virga, A.; Branzi, V. 2017. Influence of the lighting system on the driver's behavior in road tunnels: a driving simulator study, Journal of Transportation Safety \& Security 9(2): 216-238.

https://doi.org/10.1080/19439962.2016.1173155

Drakopoulos, A.; Vergou, G. 2003. Evaluation of the Converging Chevron Pavement Marking Pattern at One Wisconsin Location. AAA Foundation for Traffic Safety, Washington, DC, US. 21 p. Available from Internet: https://www.aaafoundation.org/ evaluation-converging-chevron-pavement-marking-patternone-wisconsin-location

Du, Z.; Zheng, Z.; Zheng, M.; Ran, B.; Zhao, X. 2014. Drivers' visual comfort at highway tunnel portals: A quantitative analysis based on visual oscillation, Transportation Research Part D: Transport and Environment 31: 37-47. https://doi.org/10.1016/j.trd.2014.05.012

Galante, F.; Mauriello, F.; Montella, A.; Pernetti, M.; Aria, M.; D’Ambrosio, A. 2010. Traffic calming along rural highways crossing small urban communities: driving simulator ex- periment, Accident Analysis \& Prevention 42(6): 1585-1594. https://doi.org/10.1016/j.aap.2010.03.017

Gates, T.; Qin, X.; Noyce, D. 2008. Effectiveness of experimental transverse-bar pavement marking as speed-reduction treatment on freeway curves, Transportation Research Record: Journal of the Transportation Research Board 2056: 95-103. https://doi.org/10.3141/2056-12

Georges, S.; Seriès, P.; Frégnac, Y.; Lorenceau, J. 2002. Orientation dependent modulation of apparent speed: psychophysical evidence, Vision Research 42(25): 2757-2772. https://doi.org/10.1016/S0042-6989(02)00303-6

Gilmore, D.; Bauer, K.; Torbic, D.; Kinzel, C.; Frazier, R. 2013. Treatment effects and design guidance for high- to low-speed transition zones for rural highways, Transportation Research Record: Journal of the Transportation Research Board 2348: 47-57. https://doi.org/10.3141/2348-06

Godley, S. T.; Triggs, T. J.; Fildes, B. N. 2002. Driving simulator validation for speed research, Accident Analysis \& Prevention 34(5): 589-600. https://doi.org/10.1016/S0001-4575(01)00056-2

Godley, S. T.; Triggs, T. J.; Fildes, B. N. 2000. Speed reduction mechanisms of transverse lines, Transportation Human Factors 2(4): 297-312. https://doi.org/10.1207/STHF2-4_1

Guidelines for Design of Lighting of Highway Tunnels. 2014. Professional standard of the People's Republic of China (in Chinese).

Guo, X. 2006. Research on Characteristics of the Driver's Pupil and Eye Fixation Point and Its Distribution at the Tunnel Entrance and Exit Based on Experiment: MSc dissertation, Tongji University, Shanghai, China (in Chinese).

Guo, X.; Yang, Z. 2004. Experimental Psychology. Peoples Education Press (in Chinese).

Hunter, M.; Boonsiripant, S.; Guin, A.; Rodgers, M.; Jared, D. 2010. Evaluation of effectiveness of converging chevron pavement markings in reducing speed on freeway ramps, Transportation Research Record: Journal of the Transportation Research Board 2149: 50-58. https://doi.org/10.3141/2149-06

Lewis-Evans, B.; Charlton, S. G. 2006. Explicit and implicit processes in behavioural adaptation to road width, Accident Analysis \& Prevention 38(3): 610-617.

https://doi.org/10.1016/j.aap.2005.12.005

Manser, M. P.; Hancock, P. A. 2007. The influence of perceptual speed regulation on speed perception, choice, and control: Tunnel wall characteristics and influences, Accident Analysis \& Prevention 39(1): 69-78. https://doi.org/10.1016/j.aap.2006.06.005

Park, E. S.; Carlson, P. J.; Porter, R. J.; Andersen, C. K. 2012. Safety effects of wider edge lines on rural, two-lane highways, Accident Analysis \& Prevention 48: 317-325.

https://doi.org/10.1016/j.aap.2012.01.028

Prinzmetal, W.; Beck, D. M. 2001. The tilt-consistency theory of visual illusions, Journal of Experimental Psychology: Human Perception and Performance 27(1): 206-217.

https://doi.org/10.1037/0096-1523.27.1.206

Recarte, M. A.; Nunes, L. M. 1996. Perception of speed in an automobile: estimation and production, Journal of Experimental Psychology: Applied 2(4): 291-304.

http://doi.org/10.1037/1076-898X.2.4.291

Retting, R.; McGee, H.; Farmer, C. 2000. Influence of experimental pavement markings on urban freeway exit-ramp traffic speeds, Transportation Research Record: Journal of the Transportation Research Board 1705: 116-121. https://doi.org/10.3141/1705-17 
Ryan, J.; Zanker, J. M. 2001. What determines the perceived speed of dots moving within apertures?, Experimental Brain Research 141(1): 79-87. https://doi.org/10.1007/s002210100848

Shaughnessy, J. J.; Zechmeister, E. B.; Zechmeister, J. S. 2014. Research Methods in Psychology. 10th edition. McGraw-Hill Education. 512 p.

Shen, H.; Shimodaira, Y.; Ohashi, G. 2005. Speed-tuned mechanism and speed perception in human vision, Systems and Computers in Japan 36(13): 1-12. https://doi.org/10.1002/scj.20369

Technical Standard of Highway Engineering. 2014. Professional standard of the People's Republic of China (in Chinese).

Wan, H.; Du, Z.; Ran, B.; Wang, M. 2015. Speed control method for highway tunnel safety based on visual illusion, Transportation Research Record: Journal of the Transportation Research Board 2485: 1-7. https://doi.org/10.3141/2485-01

Wan, H.; Du, Z.; Yan, Q. 2016. The speed control effect of highway tunnel sidewall markings based on color and temporal frequency, Journal of Advanced Transportation 50(7): 13521365. https://doi.org/10.1002/atr.1405

Weafer, J.; Fillmore, M. T. 2015. Alcohol-related cues potentiate alcohol impairment of behavioral control in drinkers, Psychology of Addictive Behaviors 29(2): 290-299. https://doi.org/10.1037/adb0000013

Wenderoth, P.; Burke, D. 2006. Testing the tilt-constancy theory of visual illusions, Perception 35(2): 201-213. https://doi.org/10.1068/p5388

Xia, Z.; Lv, Y.; Pan, X.; Chen, F.; Xu, M.; Wu, G.; Feng, D. 2017. Research on design pattern of city tunnel side wall based on the driver visual effect, Advances in Human Aspects of Transportation 484: 689-701. https://doi.org/10.1007/978-3-319-41682-3_58

Yeung, J. S.; Wong, Y. D.; Xu, H. 2013. Driver perspectives of open and tunnel expressways, Journal of Environmental Psychology 36: 248-256. https://doi.org/10.1016/j.jenvp.2013.09.002

Zhang, L.-X.; Liu, T.; Pan, F.-Q.; Liu, R.-C. 2014. Analysis of effects of driver factors on road traffic accident indexes, China Safety Science Journal 24(5): 79-84. (in Chinese). 